\title{
Effects of supplementing a Saccharomyces cerevisiae fermentation product during the periparturient period on performance of dairy cows fed fresh diets differing in starch content
}

\author{
W. Shi, ${ }^{1}$ C. E. Knoblock, ${ }^{1}$ K. V. Murphy, ${ }^{1}$ T. C. Bruinjé, ${ }^{1}$ I. Yoon, ${ }^{2}$ D. J. Ambrose,${ }^{1,3}$ and M. Oba ${ }^{1 *}$ \\ ${ }^{1}$ Department of Agricultural, Food and Nutritional Science, University of Alberta, Edmonton, AB, Canada T6G 2P5 \\ ${ }^{2}$ Diamond V, Cedar Rapids, IA 52404 \\ ${ }^{3}$ Livestock Research and Extension Branch, Alberta Agriculture and Forestry, Edmonton, AB, Canada T6H 5T6
}

\section{ABSTRACT}

The objective of this study was to evaluate the effects of supplementing a Saccharomyces cerevisiae fermentation product (SCFP; NutriTek, Diamond V, Cedar Rapids, IA) during the periparturient period ( $\mathrm{d}-28 \pm$ 3 to $44 \pm 3$ relative to calving) on dry matter intake (DMI), milk production, apparent total-tract nutrient digestibility, and postpartum ovarian activity of dairy cows fed fresh diets varying in starch content. From d $28 \pm 3$ before the expected calving date until d $44 \pm$ 3 after calving, 117 Holstein cows were fed diets with SCFP (SCFP; $\mathrm{n}=59$ ) or without (control, CON; $\mathrm{n}=$ 58). A common, basal, controlled-energy close-up diet (net energy for lactation: $1.43 \mathrm{Mcal} / \mathrm{kg} ; 13.8 \%$ starch) was fed before calving. Cows within each treatment (CON or SCFP) were fed either a low- (LS; $22.1 \%$ starch) or high-starch (HS; $28.3 \%$ starch) diet from d 1 to $23 \pm 3$ after calving (fresh period), resulting in 4 treatment groups: LS-CON ( $\mathrm{n}=30$ ), LS-SCFP ( $\mathrm{n}=$ $29)$, HS-CON $(\mathrm{n}=28)$, and HS-SCFP $(\mathrm{n}=30)$. All cows were fed the HS diets from d $24 \pm 3$ to $44 \pm 3$ after calving (post-fresh period). Cows were assigned to treatment balanced for parity, body condition score, body weight, and expected calving date. Milk yield was higher for cows fed the LS diets compared with those fed the HS diets during the fresh period (34.1 vs. 32.1 $\mathrm{kg} / \mathrm{d}$ ), whereas DMI and 3.5\% fat-corrected milk yield (FCM) were not affected by dietary starch content, and LS cows tended to lose more body condition than HS cows $(-0.42$ vs. -0.35 per $21 \mathrm{~d})$ during the fresh period. Overall DMI during the close-up and fresh periods did not differ between SCFP and CON cows. However, SCFP supplementation transiently increased DMI on d $1(13.0$ vs. $11.9 \mathrm{~kg} / \mathrm{d})$ and 5 (15.5 vs. $14.1 \mathrm{~kg} / \mathrm{d})$ after calving compared with CON. During the post-fresh

Received June 30, 2018.

Accepted December 7, 2018.

*Corresponding author: moba@ualberta.ca period, SCFP cows tended to eat less than CON cows (19.8 vs. $20.6 \mathrm{~kg} / \mathrm{d})$ but had similar $3.5 \%$ FCM $(44.9$ vs. $43.6 \mathrm{~kg} / \mathrm{d}$ ), resulting in greater feed efficiency for SCFP cows (FCM /DMI; 2.27 vs. 2.13). Neither starch content of fresh diets nor SCFP supplementation affected the interval from calving to first ovulation or the incidence of double ovulation. These findings suggest that feeding low-starch diets during the fresh period can increase milk production of dairy cows during the fresh period, and that supplementation of SCFP may increase feed intake around calving and feed efficiency in the post-fresh period.

Key words: calving transition, dietary starch, Saccharomyces cerevisiae fermentation product, ovulation

\section{INTRODUCTION}

Dairy cattle often experience negative energy balance during the calving transition period, which is characterized by reduced feed intake and a drastic increase in nutrient demands after the onset of lactation, contributing to a high incidence of health problems (Zaworski et al., 2014). Therefore, feeding strategies during the calving transition period should be aimed to maintain feed intake and thus reduce excessive fat mobilization. Increasing the starch content of postpartum diets is expected to reduce the extent of negative energy balance and improve performance of dairy cows by increasing energy intake. However, this approach may decrease DMI by increasing propionate flux from the rumen, according to the hepatic oxidation theory (Allen et al., 2009), and expose dairy cows to a greater risk of SARA (Stone, 2004; Penner et al., 2007). The occurrence of SARA is associated with reduced feed intake and impaired animal health (Stone, 2004; Krause and Oetzel, 2006); therefore, feeding diets high in fermentable carbohydrate during the postpartum transition period may not necessarily improve dairy cow performance. Cows in negative energy balance often manifest an 
increase in the interval from calving to first ovulation. High-starch diets reduced (Gong et al., 2002) or tended to reduce (Dyck et al., 2011) the interval from calving to first ovulation, but increased the incidence of double ovulation (Dyck et al., 2011; Subramaniam et al., 2016). Although shortening the interval from calving to first ovulation by feeding high-starch diets is an interesting concept, the increased risk of double ovulations associated with high starch intake could have negative ramifications.

Saccharomyces cerevisiae fermentation products (SCFP) have been widely used in diets of dairy cows with the aim of increasing production performance and stabilizing rumen $\mathrm{pH}$ (Erasmus et al., 2005). Several studies have reported positive effects such as increased DMI (Dann et al., 2000) and milk production (Ramsing et al., 2009; Zaworski et al., 2014) when cows were fed SCFP, whereas in other studies, SCFP supplementation did not affect DMI or milk yield (Robinson, 1997; Robinson and Garrett, 1999). In a meta-analysis study, Poppy et al. (2012) showed that supplementation with SCFP increased DMI of dairy cows in early lactation (DIM <70). However, interaction effects between fermentability of the basal diet and SCFP supplementation on DMI were not addressed. More recently, in a metabolism study with beef heifers, Shen et al. (2018) found that supplementation of a high-grain diet $(52.8 \%$ starch) with SCFP elevated the ruminal minimum $\mathrm{pH}$ and reduced the duration of $\mathrm{pH}<5.6$ by $6 \mathrm{~h}$ compared with control heifers, and also improved ruminal and total-tract NDF digestibility, suggesting that the negative effects of feeding a high-starch diet can be attenuated by supplementing SCFP. However, the interactions of dietary starch content and SCFP supplementation were not extensively studied, particularly in the immediate postpartum period.

Therefore, the objective of the current study was to evaluate the effects of SCFP supplementation during the periparturient period on DMI, milk production, apparent total-tract nutrient digestibility, and postpartum ovulation characteristics of dairy cows fed fresh diets varying in starch content. We hypothesized (1) that feeding high-starch diets during the fresh period would negatively affect performance of dairy cows compared with feeding low-starch diets, and (2) that supplementing SCFP during the periparturient period would mitigate the negative effects of feeding high-starch diets and enhance production performance of dairy cows.

\section{MATERIALS AND METHODS}

All experimental procedures used in this study were approved by the University of Alberta Animal Care and Use Committee (AUP\#1915) and conducted according to the guidelines of the Canadian Council on Animal Care (2009).

\section{Animals, Diets, and Experimental Design}

One hundred seventeen (44 primiparous and 73 multiparous) Holstein dairy cows were assigned to treatment balanced for parity, BCS, BW, and expected calving date (Table 1). Cows were enrolled into the study at d $28 \pm 3$ before expected calving date and fed diets supplemented with the $S$. cerevisiae fermentation product (SCFP; NutriTek, Diamond V, Cedar Rapids, IA; $\mathrm{n}=59)$ or without SCFP $(\mathrm{CON} ; \mathrm{n}=58)$ until d $44 \pm$ 3 after calving. The SCFP was supplemented at 0.173 and $0.095 \%$ of dietary DM in prepartum and postpartum diets, respectively. We intended to provide $19 \mathrm{~g} /$ cow per day (as-fed basis) based on expected DMI of the cows (prepartum, $11 \mathrm{~kg} /$ cow per day; postpartum, $20 \mathrm{~kg} /$ cow per day on DM basis). All cows were fed a common basal controlled-energy diet (1.43 Mcal of $\mathrm{NE}_{\mathrm{L}} / \mathrm{kg}$ of DM; $13.8 \%$ starch; Table 2 ) from $\mathrm{d}-28 \pm 3$ relative to expected calving date until parturition (the close-up period). Cows within each treatment (CON or SCFP) were fed either a low- (LS) or high-starch (HS) diet for the first $23 \pm 3 \mathrm{~d}$ after calving (fresh period), and all cows were fed the HS diets from d $24 \pm 3$ to $d$ $44 \pm 3$ after calving (post-fresh period). The timeline of experimental design is presented in Figure 1. The starch contents of the LS and HS diets were formulated to be 21 and $27 \%$ on a DM basis, respectively. Diets were formulated using dairy NRC (2001) to meet or exceed all nutrient requirements for a $650-\mathrm{kg}$ cow producing 31 (LS) or 32 (HS) kg/d of milk with $3.8 \%$ milk fat and $3.0 \%$ milk protein (Table 2). The LS diets were formulated by decreasing the starch content of HS diets primarily by replacing a portion of the barley grain with beet pulp. Throughout the study, cows were housed individually in tie-stalls and had free access to water. Cows were fed experimental diets once daily at $0730 \mathrm{~h}$ and at 105 to $110 \%$ of actual feed intake (as-fed basis) of the previous day. Feed was not pushed up because cows were fed using mangers that allow them to have full access to feed throughout the day. After calving, cows were milked in their stalls twice daily at 0330 and $1500 \mathrm{~h}$.

\section{Data and Sample Collection}

Data and samples were collected on certain day(s) of the week (e.g., Tuesday), unless noted otherwise, to facilitate routine management of the dairy operation; this protocol allowed deviations of up to $3 \mathrm{~d}$ from the target sampling day $( \pm 3 \mathrm{~d})$. The amounts of feed offered and refused were recorded daily for all cows throughout the 
Table 1. Parity, BW, and BCS of dairy cows at enrollment (d $-28 \pm$ 3 relative to expected calving date $)^{1}$

\begin{tabular}{lccccc}
\hline & \multicolumn{2}{c}{ LS } & & \multicolumn{2}{c}{ HS } \\
\cline { 2 - 3 } \cline { 5 - 6 } Variable $^{2}$ & CON & SCFP & & CON & SCFP \\
\hline 117 cows & & & & & \\
Parity & 2.3 & 2.3 & & 2.2 & 2.3 \\
BCS & 3.30 & 3.31 & & 3.24 & 3.28 \\
BW, kg & 653 & 638 & & 659 & 653 \\
38 cows & 2.0 & 2.0 & & 1.9 & 1.9 \\
Parity & 3.31 & 3.25 & & 3.35 & 3.29 \\
BCS & 639 & 620 & & 655 & 632 \\
BW, kg & & & & & \\
\hline
\end{tabular}

${ }^{1} \mathrm{LS}=$ low-starch fresh diet; $\mathrm{HS}=$ high-starch fresh diet; $\mathrm{CON}=$ control diet, no Saccharomyces cerevisiae fermentation product (SCFP) supplementation; SCFP $=$ SCFP-supplemented diet.

${ }^{2}$ The total number of animals used was 117 cows; a subset of 38 cows was used for digestibility measurement.

study. Barley silage samples were collected for 3 consecutive days weekly and composited to yield 1 sample per week. Other forage, concentrate, and TMR samples were collected once weekly. The DM concentration of individual feed ingredients was determined weekly in a forced-air oven at $55^{\circ} \mathrm{C}$ for $48 \mathrm{~h}$ and the diet formulation was adjusted if necessary. Dried samples were ground in a Wiley mill (Thomas Scientific, Philadelphia, PA) to pass through a 1-mm screen. Ground silage samples were composited monthly, straw and hay samples were composited every $2 \mathrm{mo}$, and concentrate samples were composited every 4 mo.

Milk yield was recorded daily for all cows after calving. Milk samples were collected from all cows once weekly from 2 consecutive milkings (p.m. and a.m.). Body weight and BCS were determined at the beginning of the study ( $\mathrm{d}-28 \pm 3)$, immediately after calving, at the end of $3 \mathrm{wk}(\mathrm{d} 23 \pm 3)$ after calving, and at the end of the study. Body weight was measured for 2 consecutive days before feed delivery but after morning milking (after calving). Body condition score was recorded by 3 individuals using a 5 -point scale (Wildman et al., 1982). Both BW and BCS data of each measurement point were averaged before statistical analysis, and changes in BW and BCS before and after calving were calculated. Health status were monitored daily for all cows and recorded throughout the experiment period.

Blood samples were collected from all cows before morning feeding $(\sim 0700 \mathrm{~h})$ on $\mathrm{d}-28 \pm 3,-10 \pm 3$, $7 \pm 3,21 \pm 3$, and $42 \pm 3$. In addition, d- 1 blood samples were collected within $12 \mathrm{~h}$ after calving, before cows consumed the postpartum diet. All blood samples were collected via tail blood vessel into evacuated tubes containing sodium heparin (Fisher Scientific Company, Nepean, ON, Canada) and centrifuged at 3,000 $\times g$ $\left(20 \mathrm{~min}, 4^{\circ} \mathrm{C}\right)$ immediately after collection; plasma was harvested and stored at $-20^{\circ} \mathrm{C}$ until analysis.
Changes in ovarian structures were monitored by transrectal ultrasonography (4.5- to $8.5-\mathrm{MHz}$ multifrequency transducer, Easi-Scan, BCF Technology, Rochester, MN) performed twice weekly starting at d 7 \pm 2 after calving until confirmation of first ovulation or until $44 \pm 2$ d (wk 6) postpartum, whichever occurred earlier. Major ovarian structures were recorded and ovulation was confirmed when a large follicle $(\geq 10 \mathrm{~mm})$ present at one scanning session had disappeared at the subsequent session and a corpus luteum appeared in the same location. If 2 or more large follicles disappeared, replaced by an equal number of corpora lutea, double ovulation was declared.

A subset of 38 cows was selected after balancing parity, BCS, BW, and expected calving date (Table 1). For those 38 cows, apparent total-tract digestibilities of $\mathrm{DM}, \mathrm{OM}, \mathrm{NDF}$, and starch were determined on wk 1 and 3 after calving. Fecal grab samples were collected on d 7 to $9 \pm 3$ (wk 1) and d 21 to $23 \pm 3$ (wk 3) after calving every $9 \mathrm{~h}$ for 3 -d periods to obtain a representative sample accounting for every $3 \mathrm{~h}$ of a 24 -h period. Fecal samples were composited for each cow at each sampling period and dried in a forced-air oven for $72 \mathrm{~h}$ at $55^{\circ} \mathrm{C}$. Samples of feed ingredients were collected for 3 consecutive days weekly and composited to yield 1 sample per week and dried in a forced-air oven at $55^{\circ} \mathrm{C}$ for $48 \mathrm{~h}$. Fecal and feed ingredients samples were then ground to pass through a 1-mm screen (Wiley mill, Thomas Scientific). Weekly feed ingredient samples were composited by load of feed delivered to the farm (barley silage, $\mathrm{n}=9$; alfalfa hay, $\mathrm{n}=12$; concentrates, $\mathrm{n}=3$ to 6$)$.

\section{Sample Analyses}

Milk samples were analyzed for concentrations of CP, fat, lactose, SCC, and MUN by infrared spectroscopy (AOAC International, 2002; method 972.16; MilkoScan 605, Foss North America, Brampton, ON, Canada) at the Alberta Central Milk Testing Laboratory (Edmonton, AB, Canada). The 3.5\% FCM was calculated as $0.432 \times$ milk yield $+16.23 \times$ fat yield; and $\mathrm{SCM}$ yield was calculated as $12.3 \times$ fat yield $+6.56 \times \mathrm{SNF}$ yield $-0.0752 \times$ milk yield (Tyrrell and Reid, 1965).

Plasma glucose concentration was analyzed using a glucose oxidase/peroxidase enzyme (No. P7119; Sigma Co., St. Louis, MO) and dianisidine dihydrochloride (No. F5803; Sigma Co.). Absorbance was determined by using a plate reader (SpectraMax 190; Molecular Devices Crop., Sunnyvale, CA) at a wavelength of $450 \mathrm{~nm}$. Plasma free fatty acid concentration was determined using a commercial kit (NEFA HR2; Wako Chemicals USA Inc., Richmond, VA). Plasma BHB concentration was measured by the enzymatic oxidation of $\mathrm{BHB}$ 
Table 2. Ingredient and chemical composition (\% of DM unless otherwise noted) of experimental diets ${ }^{1}$

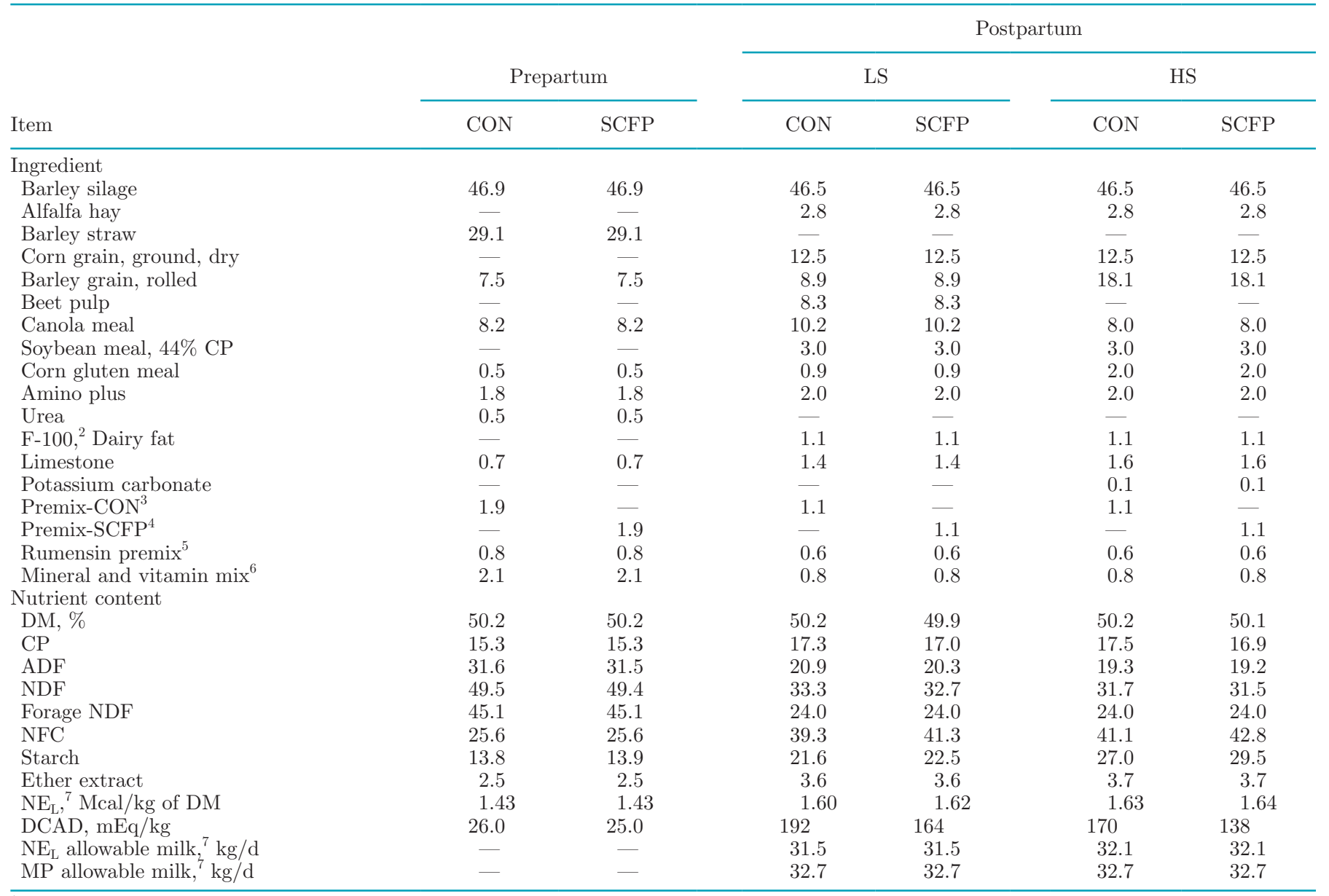

${ }^{1} \mathrm{CON}=$ control diet, no Saccharomyces cerevisiae fermentation product (SCFP) supplementation; Premix-CON was used in the diet; SCFP = SCFP-supplemented diet; Premix-SCFP was used in the diet; LS = low-starch diets; HS = high-starch diets.

${ }^{2}$ F-100 Dairy Fat (Pro-Ag, Winnipeg, MB, Canada).

${ }^{3}$ Contained $99.0 \%$ of dry ground corn grain and $1.0 \%$ of canola oil, providing $0 \mathrm{~g} / \mathrm{d}$ of SCFP.

${ }^{4}$ Contained $91.1 \%$ of dry ground corn grain, $7.9 \%$ of SCFP, and $1.0 \%$ of canola oil, providing $19 \mathrm{~g} / \mathrm{cow}$ per day of SCFP (as-fed basis) based on expected DMI of cows (11 kg/cow per day before calving; $20 \mathrm{~kg} /$ cow per day after calving).

${ }^{5}$ Contained 1.2\% Rumensin (Elanco Animal Health, Greenfield, IN), 97.5\% dry ground barley grain, and $1.3 \%$ canola oil.

${ }^{6}$ Contained $11.0 \% \mathrm{Ca}, 2.78 \% \mathrm{Na}, 14.2 \% \mathrm{Cl}, 11.8 \% \mathrm{Mg}, 7.68 \% \mathrm{~S}, 16.2 \mathrm{mg} / \mathrm{kg}$ of Mn, $4.88 \mathrm{mg} / \mathrm{kg}$ of I, $1,212 \mathrm{kIU} / \mathrm{kg}$ of vitamin A, $121 \mathrm{kIU} / \mathrm{kg}$ of vitamin $\mathrm{D}$, and 4,040 IU $/ \mathrm{kg}$ of vitamin $\mathrm{E}$ for close-up diet; contained $0.71 \% \mathrm{Ca}, 24.3 \% \mathrm{Na}, 39.4 \% \mathrm{Cl}, 13.0 \% \mathrm{Mg}, 0.13 \% \mathrm{~S}, 2,427 \mathrm{mg} / \mathrm{kg}$ of $\mathrm{Cu}$, $4,244 \mathrm{mg} / \mathrm{kg}$ of Mn, $174 \mathrm{mg} / \mathrm{kg}$ of Co, $4,583 \mathrm{mg} / \mathrm{kg}$ of Zn, $10.0 \mathrm{mg} / \mathrm{kg}$ of Se, $85.0 \mathrm{mg} / \mathrm{kg}$ of I, $543 \mathrm{kIU} / \mathrm{kg}$ of vitamin A, $155 \mathrm{kIU} / \mathrm{kg}$ of vitamin $\mathrm{D}$, and $5,118 \mathrm{IU} / \mathrm{kg}$ of vitamin $\mathrm{E}$ for postpartum diets.

${ }^{7}$ Estimated from NRC (2001).

to acetoacetate in the presence of 3-hydroxybutyrate dehydrogenase (No. H6501; Roche, Mississauga, ON, Canada) followed by determination of NADH production at a wavelength of $340 \mathrm{~nm}$.

Feed and fecal samples were sent to Cumberland Valley Analytical Services (Hagerstown, MD), and analyzed for DM (AOAC International, 2002; method 930.15), OM (AOAC International, 2002; method 942.05), NDF (Van Soest et al., 1991), starch (Hall, 2009), and CP (AOAC International, 2000; method 990.03). Indigestible NDF was determined after $288 \mathrm{~h}$ of in situ digestion using a ruminally cannulated dry cow fed a TMR containing $59.4 \%$ triticale silage, $25.5 \%$ barley straw, $4.24 \%$ rolled barley, $4.24 \%$ canola meal, $5.94 \%$ barley malt sprouts, and $0.68 \%$ minerals and vitamins with $50 \%$ dietary NDF content (all on a DM basis) with a method adapted from Huhtanen et al. (1994), and used as an internal marker to estimate fecal output (Cochran et al., 1986).

\section{Statistical Analysis}

Statistical analyses were conducted using the Fit Model procedure of JMP 13 and SAS 9.2 (SAS Insti- 
Close-up period $\mathrm{d}-28 \pm 3$ relative to expected calving date to parturition
Fresh period

d 1 to $23 \pm 3$ relative to actual calving date
Post-fresh period

d $24 \pm 3$ to $44 \pm 3$ relative

to actual calving date

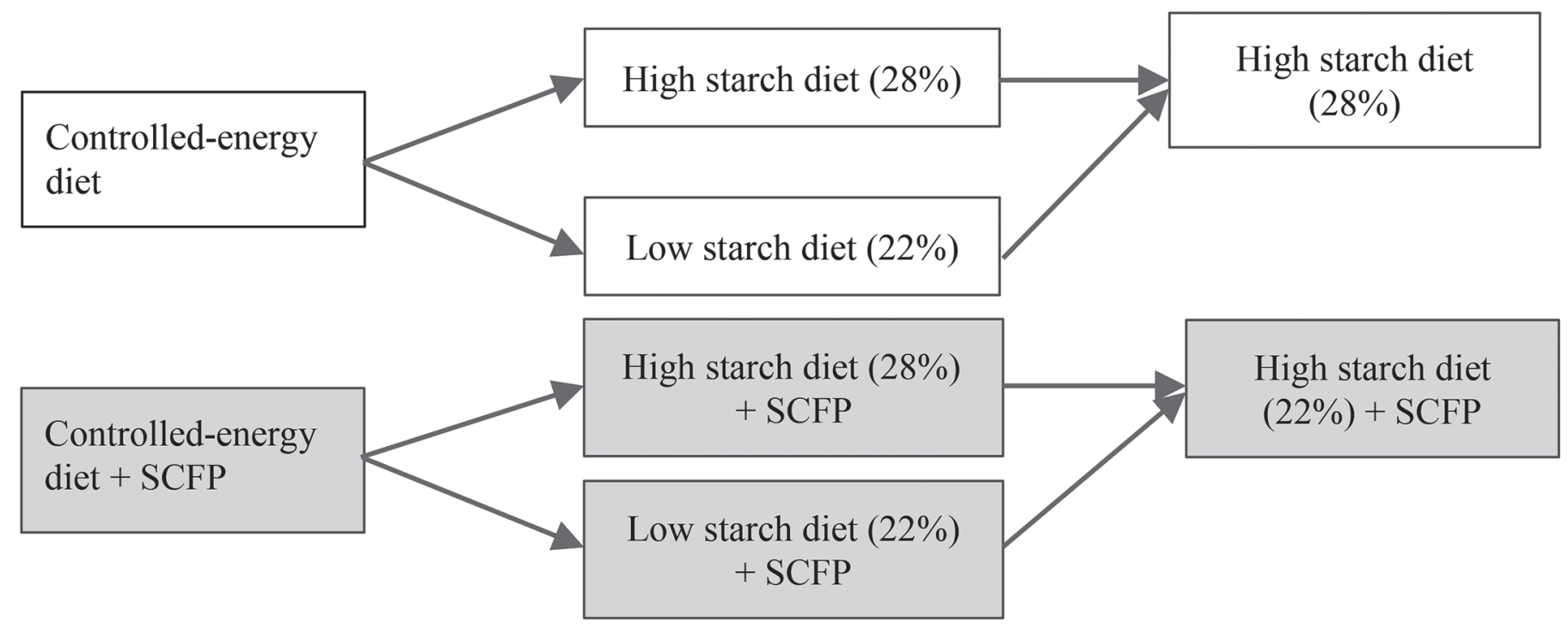

Figure 1. Timeline of experimental design. SCFP $=$ Saccharomyces cerevisiae fermentation product.

tute Inc., Cary, NC). Data were analyzed separately for close-up, fresh (d 1 to $23 \pm 3$ ), and post-fresh (d 24 to $44 \pm 3$ ) periods. Prepartum and postpartum data (both fresh and post-fresh periods) were analyzed using the following models [1] and [2], respectively:

$$
\begin{gathered}
Y_{i k l}=\mu+T_{i}+P_{k}+W_{l}+T P_{i k}+T W_{i l} \\
+P W_{k l}+e_{i k l}, \\
Y_{i j k l}=\mu+T_{i}+S_{j}+P_{k}+W_{l}+T S_{i j}+T P_{i k}+T W_{i l} \\
+S P_{j k}+S W_{j l}+P W_{k l}+T S W_{i j l}+e_{i j k l},
\end{gathered}
$$

where $Y_{i j k}=$ observations for dependent variables, $\mu=$ overall mean, $T_{i}=$ fixed effect of SCFP supplementation (CON or SCFP), $S_{j}=$ fixed effects or carryover effects of starch content of fresh diets (LS or HS), $P_{k}$ $=$ fixed effect of parity (primiparous or multiparous), $W_{l}=$ fixed effect of week relative to parturition as a repeated measure, $T P_{i k}=$ effect of SCFP and parity interaction, $T W_{i l}=$ effect of SCFP and week interaction, $P W_{k l}=$ effect of parity and week interaction, $T S_{i j}$ $=$ effect of SCFP and starch content interaction, $S P_{j k}$ $=$ effect of starch content and parity interaction, $S W_{j l}$ $=$ effect of starch content and week interaction, $T S W_{i j l}$ $=$ effect of SCFP, starch content, and week interaction, and $e_{i j k l}=$ residuals. Because cows were fed the LS or
HS fresh diet until d $23 \pm 3$, and the post-fresh period (wk 4-6) started on a certain day of the week (i.e., Friday; allowing a deviation of up to $3 \mathrm{~d}$ from the target day relative to calving), wk $1,2,3,4,5$, and 6 were defined as $\mathrm{d} 1$ to $7, \mathrm{~d} 8$ to 14 , d 15 to $\mathrm{d} 23 \pm 3$, d $24 \pm$ 3 to $30 \pm 3$, d $31 \pm 3$ to $37 \pm 3$, and d $38 \pm 3$ to $44 \pm$ 3 after calving, respectively.

The repeated measure was used for variables measured over time, such as DMI, milk yield and components, and feed efficiency using the REPEATED statement in the MIXED procedure of SAS. The covariance structure with the smallest Akaike's information criterion was used (Littell et al., 1996). For variables not measured over time, such as BW and BCS changes and plasma metabolites, data were analyzed using JMP 13 , and the effect of time relative to parturition and all associated interactions were removed from the model. When an interaction between starch content and SCFP supplementation was detected, comparisons among treatments were conducted using Student's $t$-test.

In addition, treatment effects on days to first ovulation were determined by ANOVA using the MIXED procedure of SAS using the postpartum model [2] above with minor modifications, excluding the effects of week and its interactions. Post hoc tests were performed using the Tukey-Kramer option. Similarly, the occurrence of double ovulation, as a binary outcome, was 
Table 3. Effects of supplementation with a Saccharomyces cerevisiae fermentation product (SCFP) on DMI and BCS changes during the close-up period ${ }^{1}$

\begin{tabular}{lcccc}
\hline Variable & CON & SCFP & SE & $P$-value \\
\hline DMI, kg/d & 11.0 & 11.2 & 0.26 & 0.61 \\
${\text { BCS change }{ }^{2} / 21 \mathrm{~d}}^{2}$ & -0.02 & -0.03 & 0.03 & 0.68 \\
\hline
\end{tabular}

${ }^{1} \mathrm{CON}=$ control diet, no SCFP supplementation; SCFP = SCFP-supplemented diet.

${ }^{2} \mathrm{BCS}$ used for calculation were measured at the time of enrollment $(\mathrm{d}-28 \pm 3)$ and immediately after calving $(\mathrm{d} 1 \pm 1)$.

evaluated using a logistic regression model (GLIMMIX procedure). Treatment effects on days to first ovulation were also determined using Kaplan-Meier survival analysis (LIFETEST procedure) and Cox proportional hazard models (PHREG procedure), where associations between BCS categories and days to first ovulation were also explored.

For all response variables, significance was declared at $P \leq 0.05$ and tendency was declared at $0.05<P \leq$ 0.10 .

\section{RESULTS}

One hundred and twenty-eight cows had been initially assigned to treatments, but 2 cows that were not fed close-up diets for more than 2 wk due to unexpected early calving and 9 cows that had severe health problems immediately after calving (1 metritis, 1 mastitis, 2 milk fever, 2 fatty liver, and 3 leg injuries; 2 and 7 cows were on CON and SCFP before calving, respectively) were removed from the study, leaving 117 cows for the statistical analyses. The starch content of fresh diets, calculated from analyses of feed ingredients, was as follows: LS-CON, $21.6 \%$ starch; LS-SCFP, $22.5 \%$ starch; HS-CON, 27.0\% starch; and HS-SCFP, 29.5\% starch. Starch content of the HS-SCFP diet was likely overestimated because of a sampling error of the concentrate mix stored in a different type of feed bin where access for sampling is difficult.

\section{Animal Responses During the Close-Up Period}

We detected no differences in DMI and BCS changes between SCFP and CON groups during the close-up period (Table 3). Initial plasma concentrations of glucose, free fatty acids, and BHB did not differ between SCFP and CON cows, and they were not affected by SCFP supplementation on $\mathrm{d}-10$ and $\mathrm{d}+1$ relative to calving (Table 4).

\section{Animal Responses During the Fresh Period}

$D M I, B W, B C S$, and Milk Production. Interactions between dietary starch content and SCFP supplementation were not detected for DMI, BW, BCS, or milk yield (Table 5). All cows, regardless of treatment, increased DMI during the fresh period (week effect: $P$ $<0.0001$ ). Overall DMI and BW changes were not affected by starch content of fresh diets, but milk yield was higher $(34.1$ vs. $32.1 \mathrm{~kg} / \mathrm{d} ; P<0.05)$ and BCS loss tended to be greater $(-0.42$ vs. $-0.35 / 21 \mathrm{~d} ; P=0.06)$ for cows fed LS than HS diets. In addition, a starch $x$ week interaction was noted for milk yield during the fresh period $(P=0.04)$, suggesting that cows fed LS

Table 4. Effects of supplementation with a Saccharomyces cerevisiae fermentation product (SCFP) on plasma metabolite concentrations on $\mathrm{d}-28,-10$, and +1 relative to calving ${ }^{1}$

\begin{tabular}{lcccc}
\hline Variable & CON & SCFP & SE & $P$-value \\
\hline $\mathrm{d}-28$ & 70.2 & 67.9 & 1.25 & 0.20 \\
Glucose, mg/dL & 169 & 169 & 13.9 & 0.98 \\
Free fatty acids, $\mu \mathrm{Eq} / \mathrm{L}$ & 7.41 & 7.15 & 0.20 & 0.36 \\
BHB, mg/dL & 66.9 & 68.3 & 1.73 & 0.59 \\
$\mathrm{~d}-10$ & 272 & 241 & 21.3 & 0.30 \\
Glucose, $\mathrm{mg} / \mathrm{dL}$ & 7.23 & 6.87 & 0.23 & 0.26 \\
Free fatty acids, $\mu \mathrm{Eq} / \mathrm{L}$ & 87.8 & 87.7 & 3.81 & 1.00 \\
BHB, mg/dL & 373 & 396 & 29.4 & 0.59 \\
$\mathrm{~d}+1^{2}$ & 8.91 & 8.49 & 0.27 & 0.29 \\
Glucose, mg/dL & Free fatty acids, $\mu \mathrm{Eq} / \mathrm{L}$ & & & \\
BHB, mg/dL & & & & \\
\hline
\end{tabular}

${ }^{1} \mathrm{CON}=$ control diet, no SCFP supplementation; SCFP = SCFP-supplemented diet.

${ }^{2}$ Blood samples on $\mathrm{d}+1$ were collected within $12 \mathrm{~h}$ after calving and before postpartum diets were fed. 
diets had a faster increase in milk production. However, yields of milk components, $3.5 \%$ FCM, and SCM were not affected by starch content, resulting in similar feed efficiency (3.5\% FCM/DMI) between dietary starch treatments. A tendency for an interaction between SCFP and day was observed $(P=0.08$; Figure 2$)$, and DMI at $\mathrm{d} 1(13.0$ vs. $11.9 \mathrm{~kg} / \mathrm{d} ; P=0.02)$ and $\mathrm{d} 5(15.5$ vs. $14.1 \mathrm{~kg} / \mathrm{d} ; P=0.04)$ were greater for SCFP cows than for CON cows. Supplementation of SCFP did not affect overall DMI, BW change, or BCS change during the fresh period. Yields of milk, milk components, $3.5 \%$ FCM, and SCM during the fresh period were also not affected by SCFP supplementation.

Interactions between dietary starch content and SCFP supplementation were detected for concentrations of milk fat $(P=0.03)$, total solids $(P=0.04)$, and MUN $(P=0.02)$. Within cows fed CON, feeding the LS postpartum diet decreased concentration of milk fat and total solids compared with feeding the HS diet. Supplementation of SCFP increased concentration of total solids compared with CON within cows fed LS

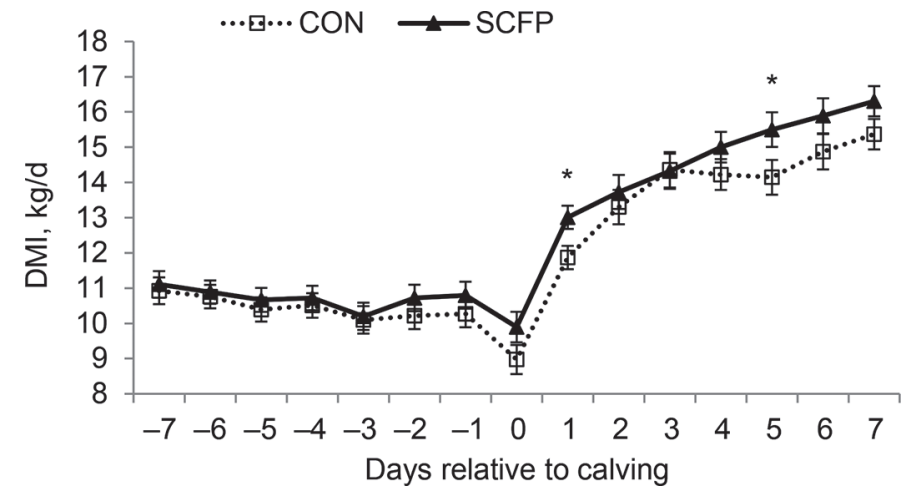

Figure 2. Daily DMI of cows supplemented with Saccharomyces cerevisiae fermentation product (SCFP) or not $(\mathrm{CON})$ and fed either a low- or high-starch diet after calving. The $P$-values for SCFP, day, and their interaction during $\mathrm{d}-7$ to 0 relative to parturition were $0.44,<0.01$, and 0.82 , respectively. No interaction was observed for starch content $\times \operatorname{SCFP}(P=0.47)$ or starch content $\times$ day $(P=0.15)$ during $\mathrm{d} 1$ to 7 after calving. The $P$-values for SCFP, day, and their interaction during d 1 to 7 after calving were $0.10,<0.01$, and 0.08 , respectively. Data were analyzed individually for each time point using Student's $t$-test. *Effects of SCFP on DMI were significant $(P<0.05)$ on $\mathrm{d} 1$ and 5 after calving. Data shown are LSM \pm SE.

Table 5. Effects of starch content of fresh diets (ST) and supplementation of a Saccharomyces cerevisiae fermentation product (SCFP) on DMI, BW and BCS changes, and milk yield and composition of dairy cows during the fresh period (d 1 to $23 \pm 3$ after calving) ${ }^{1}$

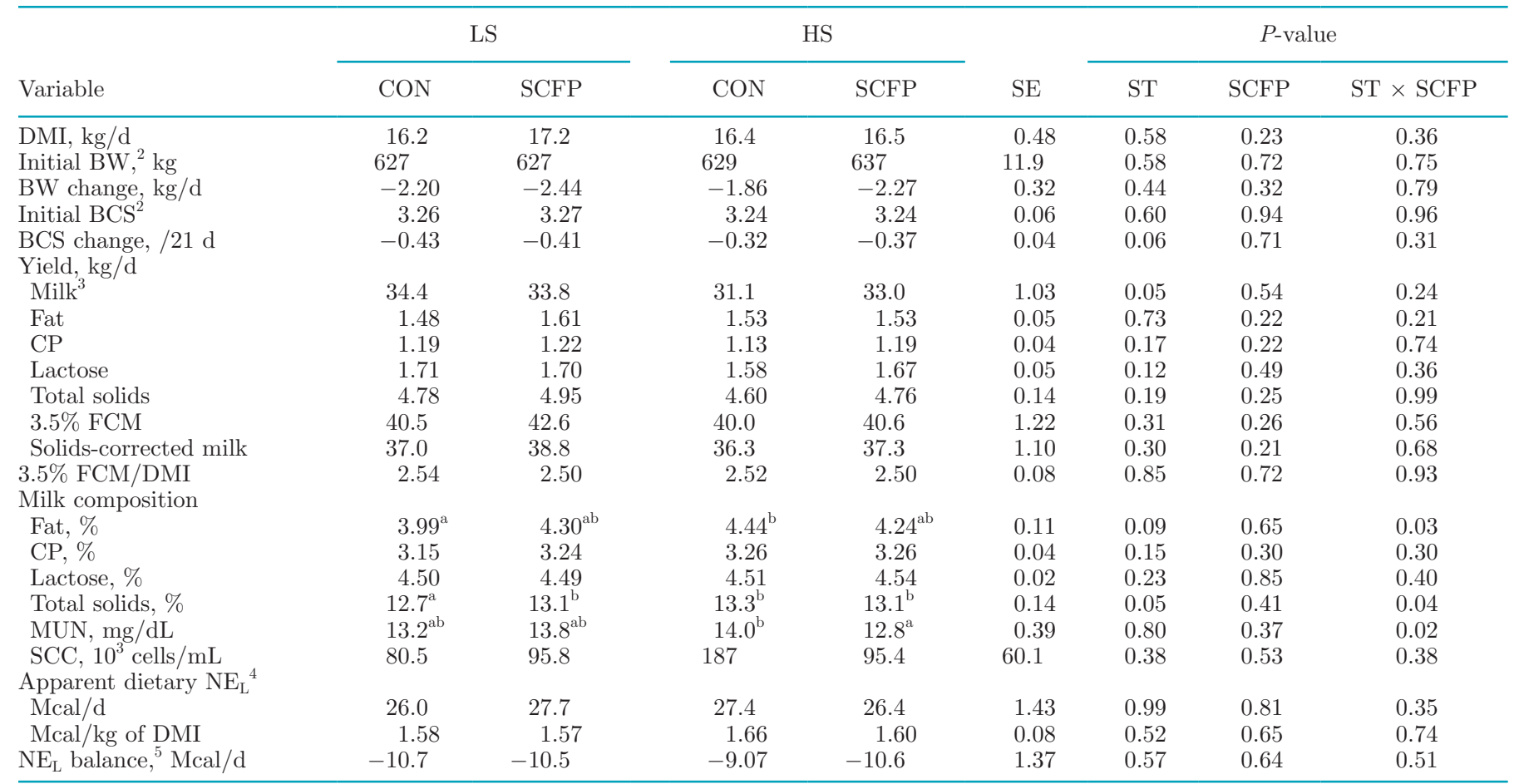

${ }^{\mathrm{a}, \mathrm{b}}$ Means in the same row with different superscripts differ significantly $(P<0.05)$ when an interaction of main treatment effect was observed. ${ }^{1} \mathrm{LS}=$ low-starch fresh diets; HS = high-starch fresh diets; CON = control diet, no SCFP supplementation; SCFP $=\mathrm{SCFP}$-supplemented diet.

${ }^{2}$ Measured immediately after calving.

${ }^{3}$ Week $\times \mathrm{ST} ; P=0.04$.

${ }^{4}$ Calculated according to Dann et al. (2000).

${ }^{5}$ Apparent dietary $\mathrm{NE}_{\mathrm{L}}(\mathrm{Mcal} / \mathrm{d})$ minus $\mathrm{NE}_{\mathrm{L}}$ required for milk output and maintenance $(\mathrm{Mcal} / \mathrm{d})$. The $\mathrm{NE}_{\mathrm{L}}$ required for milk and maintenance were calculated according to Dann et al. (2000). 
Table 6. Effects of starch content of fresh diets (ST) and supplementation of a Saccharomyces cerevisiae fermentation product (SCFP) on plasma metabolite concentrations on $\mathrm{d} 7 \pm 3$ and $21 \pm 3$ after calving ${ }^{1}$

\begin{tabular}{|c|c|c|c|c|c|c|c|c|}
\hline \multirow[b]{2}{*}{ Variable } & \multicolumn{2}{|c|}{ LS } & \multicolumn{2}{|c|}{ HS } & \multirow[b]{2}{*}{$\mathrm{SE}$} & \multicolumn{3}{|c|}{$P$-value } \\
\hline & $\mathrm{CON}$ & SCFP & $\mathrm{CON}$ & SCFP & & $\mathrm{ST}$ & SCFP & $\mathrm{ST} \times \mathrm{SCFP}$ \\
\hline Glucose, mg/dL & 58.5 & 56.2 & 61.0 & 59.6 & 1.52 & 0.05 & 0.23 & 0.75 \\
\hline Free fatty acids, $\mu \mathrm{Eq} / \mathrm{L}$ & $568^{\mathrm{a}}$ & $423^{\mathrm{b}}$ & $386^{\mathrm{b}}$ & $463^{\mathrm{ab}}$ & 50.7 & 0.16 & 0.50 & 0.03 \\
\hline $\begin{array}{l}\mathrm{BHB}, \mathrm{mg} / \mathrm{dL} \\
\mathrm{d} 21\end{array}$ & 9.34 & 8.44 & 9.23 & 8.51 & 0.64 & 0.98 & 0.20 & 0.90 \\
\hline $\mathrm{BHB}, \mathrm{mg} / \mathrm{dL}$ & 9.66 & 10.2 & 8.30 & 8.02 & 0.73 & 0.01 & 0.83 & 0.54 \\
\hline
\end{tabular}

${ }^{\mathrm{a}, \mathrm{b}}$ Means in the same row with different superscripts differ significantly $(P<0.05)$ when an interaction of main treatment effect was observed. ${ }^{1} \mathrm{LS}=$ low-starch fresh diets; HS = high-starch fresh diets; CON = control diet, no SCFP supplementation; SCFP $=$ SCFP-supplemented diet

postpartum diet. The concentration of MUN was lower for cows fed SCFP than for those fed CON when the HS diet was fed during the fresh period.

Plasma Metabolites and Health Disorders. We detected no interactions between dietary starch content and SCFP supplementation for plasma concentrations of glucose and BHB on d $7 \pm 3$ and $21 \pm 3$ after calving (Table 6). Interactions of dietary starch content and SCFP supplementation were noted for plasma free fatty acids concentration on both $\mathrm{d} 7 \pm 3$ and $\mathrm{d} 21$ \pm 3 after calving $(P<0.05)$. Cows fed LS diets had higher plasma free fatty acids concentration than HS cows only within the CON group. Plasma free fatty acids were lower for SCFP cows than for CON on d $7 \pm$ 3 , but only in cows fed the LS diet. Cows fed LS diets had lower plasma glucose concentrations on $\mathrm{d} 7 \pm 3$ ( 57.3 vs. $60.3 \mathrm{mg} / \mathrm{dL} ; P=0.05)$ and $\mathrm{d} 21 \pm 3$ (58.8 vs. $63.9 \mathrm{mg} / \mathrm{dL} ; P<0.01)$ than those fed HS diets during the fresh period. Plasma BHB concentration was not affected by starch content on d $7 \pm 3$, but cows fed LS diets had higher plasma BHB than HS cows on d $21 \pm$ 3 (9.95 vs. $8.16 \mathrm{mg} / \mathrm{dL} ; P=0.01)$. Supplementation of SCFP did not affect plasma glucose on $\mathrm{d} 7 \pm 3$ or $\mathrm{d}$ $21 \pm 3$ after calving. Supplementation of SCFP had no effect on plasma BHB on either d $7 \pm 3$ or d $21 \pm 3$. Incidences of health disorders were 27 and 26 cases for LS and HS cows, respectively, and 33 and 20 cases for CON and SCFP cows, respectively (Table 7).

Digestibility. Interactions between dietary starch content and SCFP supplementation were not detected for any digestibility measurements (Table 8). Starch content had no effect on apparent total-tract $\mathrm{OM}$ or DM digestibility; however, apparent total-tract NDF digestibility was greater for LS cows than for HS cows (40.7 vs. $35.3 \% ; P=0.01$ ) on $\mathrm{d} 7$. There was an interaction between dietary starch treatment and parity $(P$ $<0.01$ ). Apparent total-tract starch digestibility was greater for LS diets in multiparous cows on d 7 (98.7 vs. $97.8 \% ; P=0.01)$ and 21 (98.7 vs. $97.7 \% ; P<0.01$, but lower for LS diets in primiparous cows on d 7 (98.6

Table 7. Incidence of health disorders during $\mathrm{d} 1$ to $44 \pm 3$ after calving ${ }^{1,2}$

\begin{tabular}{|c|c|c|c|c|}
\hline \multirow[b]{2}{*}{ Item } & \multicolumn{2}{|c|}{ LS } & \multicolumn{2}{|c|}{ HS } \\
\hline & $\mathrm{CON}$ & SCFP & $\mathrm{CON}$ & SCFP \\
\hline Subclinical ketosis ${ }^{3}$ & 7 & 2 & 5 & 3 \\
\hline Displaced abomasum & 3 & 1 & 2 & 0 \\
\hline Metritis & 2 & 3 & 1 & 2 \\
\hline Retain placenta & 3 & 0 & 4 & 5 \\
\hline Mastitis & 3 & 1 & 1 & 0 \\
\hline Hypocalcemia & 1 & 0 & 0 & 3 \\
\hline Foot problem & 1 & 3 & 1 & 1 \\
\hline Edema & 1 & 0 & 0 & 0 \\
\hline Liver abscess & 0 & 1 & 0 & 0 \\
\hline Total cases of health disorders & 21 & 11 & 14 & 14 \\
\hline \multicolumn{5}{|c|}{$\begin{array}{l}{ }^{1} \text { There were } 53 \text { cases of health disorders during wk } 1 \text { to } 3 \text {, and } 7 \text { cases of health problems during wk } 4 \text { to } 6 . \\
\text { The number of health problems was } 20,7,13 \text {, and } 13 \text { during wk } 1 \text { to } 3 \text {, and was } 1,4,1 \text {, and } 1 \text { during wk } 4 \text { to } \\
6 \text {, respectively, for LS-CON, LS-SCFP, HS-CON, and HS-SCFP. } \\
{ }^{2} \text { LS = low-starch fresh diets; HS = high-starch fresh diets; CON = control diet, no SCFP supplementation; } \\
\text { SCFP = SCFP-supplemented diet. }\end{array}$} \\
\hline
\end{tabular}


Table 8. Effects of starch content of fresh diets (ST) and supplementation of a Saccharomyces cerevisiae fermentation product (SCFP) on apparent total-tract DM, OM, NDF, and $\operatorname{starch}^{1}$ digestibility on $\mathrm{d} 7 \pm 3$ and $21 \pm 3$ after calving ${ }^{1,2}$

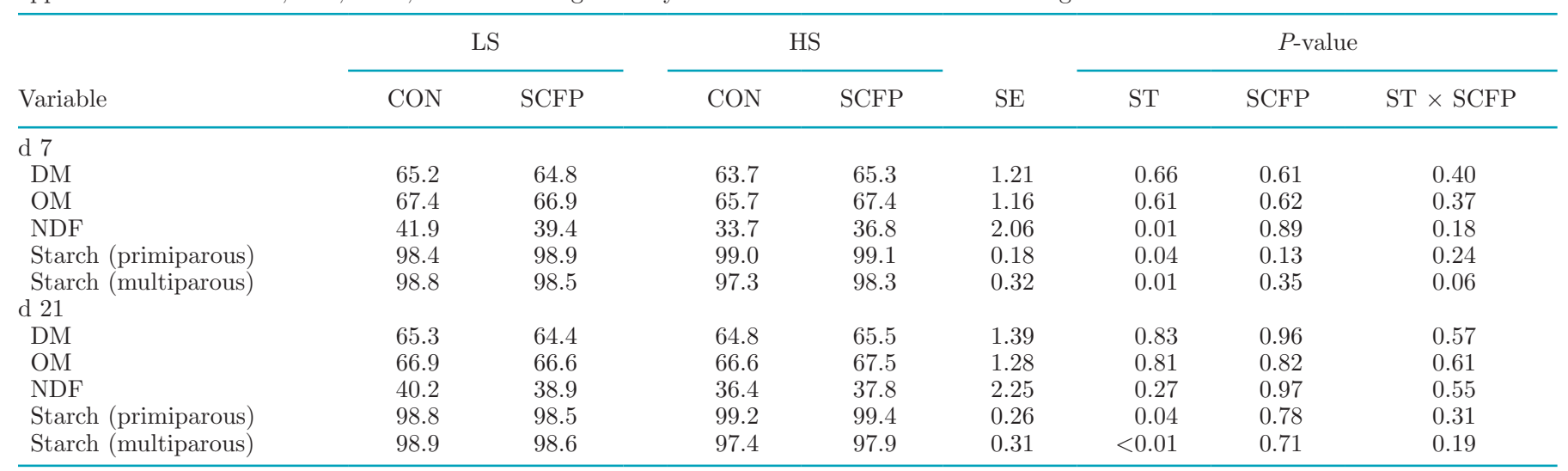

${ }^{1} \mathrm{LS}=$ low-starch fresh diets; HS = high-starch fresh diets; CON = control diet, no SCFP supplementation; SCFP = SCFP-supplemented diet

${ }^{2}$ Interaction between dietary starch treatment and parity $(P<0.01)$.

vs. $99.1 \% ; P=0.04)$ and 21 (98.7 vs. $99.3 \% ; P=0.04)$. Supplementation with SCFP did not affect apparent total-tract DM, OM, or NDF digestibility.

\section{Animal Responses After the Fresh Period}

DMI and Milk Production. All animals were fed HS diets during the post-fresh period, and effects of dietary starch content described in this section are carryover effects from the fresh period. We did not detect interactions between carryover effects of starch content of fresh diets and SCFP supplementation for DMI and milk yield (Table 9). Overall DMI during the post-fresh period was not affected by starch content of fresh diets, but cows fed LS fresh diets tended to have higher milk yield ( 42.2 vs. $40.3 \mathrm{~kg} / \mathrm{d} ; P=0.09)$ than those fed HS diets during the post-fresh period. Yields of milk components during the post-fresh period, however, were not affected by the starch content of fresh diets. Although cows supplemented with SCFP tended to have lower DMI $(19.8$ vs. $20.6 \mathrm{~kg} / \mathrm{d} ; P=0.01)$ than those fed CON, yields of milk, milk components, $3.5 \%$ FCM, and SCM were not affected by SCFP supplementation, resulting in increased $3.5 \% \mathrm{FCM} / \mathrm{DMI}$ (2.27 vs. $2.12 ; P$ $<0.01)$. The changes in BW and BCS during the postfresh period were not affected by starch content of fresh diets or SCFP supplementation. Apparent dietary $\mathrm{NE}_{\mathrm{L}}$ density, calculated from energy in actual milk production, maintenance, and energy provided or required by BW change (Dann et al., 2000), was not affected by starch content, but it was greater for cows fed SCFP compared with those fed CON (2.07 vs. $1.97 \mathrm{Mcal} / \mathrm{kg}$ of DM; $P=0.05)$.

Tendencies of interactions between the starch content of fresh diets and SCFP supplementation were detected for concentrations of milk fat $(P=0.08)$, total solids $(P=0.08)$, MUN $(P=0.09)$, and SCC $(P$ $=0.07)$ during the postfresh period. Within cows fed CON, concentrations of milk fat and total solids were lower for cows fed the LS postpartum diet compared with cows fed the HS diet. Concentration of total solids was greater for SCFP cows versus CON within cows fed the LS postpartum diet. Concentration of MUN was lower for the cows fed SCFP versus CON when the HS diet was fed during the immediate postpartum period. Within the CON group, SCC was lower for LS cows than HS cows. In addition, SCC tended to be lower for SCFP cows versus CON within cows fed the HS postpartum diet $(P=0.07)$.

Plasma Metabolites. Interactions of starch content of fresh diets and SCFP supplementation existed for concentrations of plasma free fatty acids $(P<0.01)$ and BHB $(P=0.03)$ on $d 42 \pm 3$. Concentrations of plasma free fatty acids were lower in SCFP cows than in CON cows, but only for cows fed LS fresh diets. Plasma BHB was also lower in cows that received SCFP supplementation compared with $\mathrm{CON}$ but the effect was mostly derived from cows fed the HS fresh diets. Cows fed LS fresh diets tended to have lower plasma glucose than those fed HS fresh diets $(62.0$ vs. $65.2 \mathrm{mg} / \mathrm{dL} ; P=0.06$; Table 10). Plasma glucose at d $42 \pm 3$ after calving $(66.5$ vs. $60.8 \mathrm{mg} / \mathrm{dL} ; P<0.01)$ was increased in cows that received SCFP supplementation.

Reproduction. Neither starch content of fresh diets nor SCFP supplementation affected days to first ovulation, but primiparous cows tended to have a longer interval from calving to first ovulation than multiparous cows (27.2 vs. $22.4 ; P=0.06)$. Survival probability curves of days to first ovulation up to 42 DIM according to categories of starch content of fresh diets (LS vs. HS), SCFP supplementation (CON vs. SCFP), parity (multiparous vs. primiparous), and BCS at 42 DIM 
Table 9. Effects of supplementation of a Saccharomyces cerevisiae fermentation product (SCFP) and carryover effects of starch content of fresh diets (ST) on DMI, BW and BCS changes, milk yield and composition during the post-fresh period (d $24 \pm 3$ to $44 \pm 3$ after calving), and the interval from calving to first ovulation postpartum ${ }^{1}$

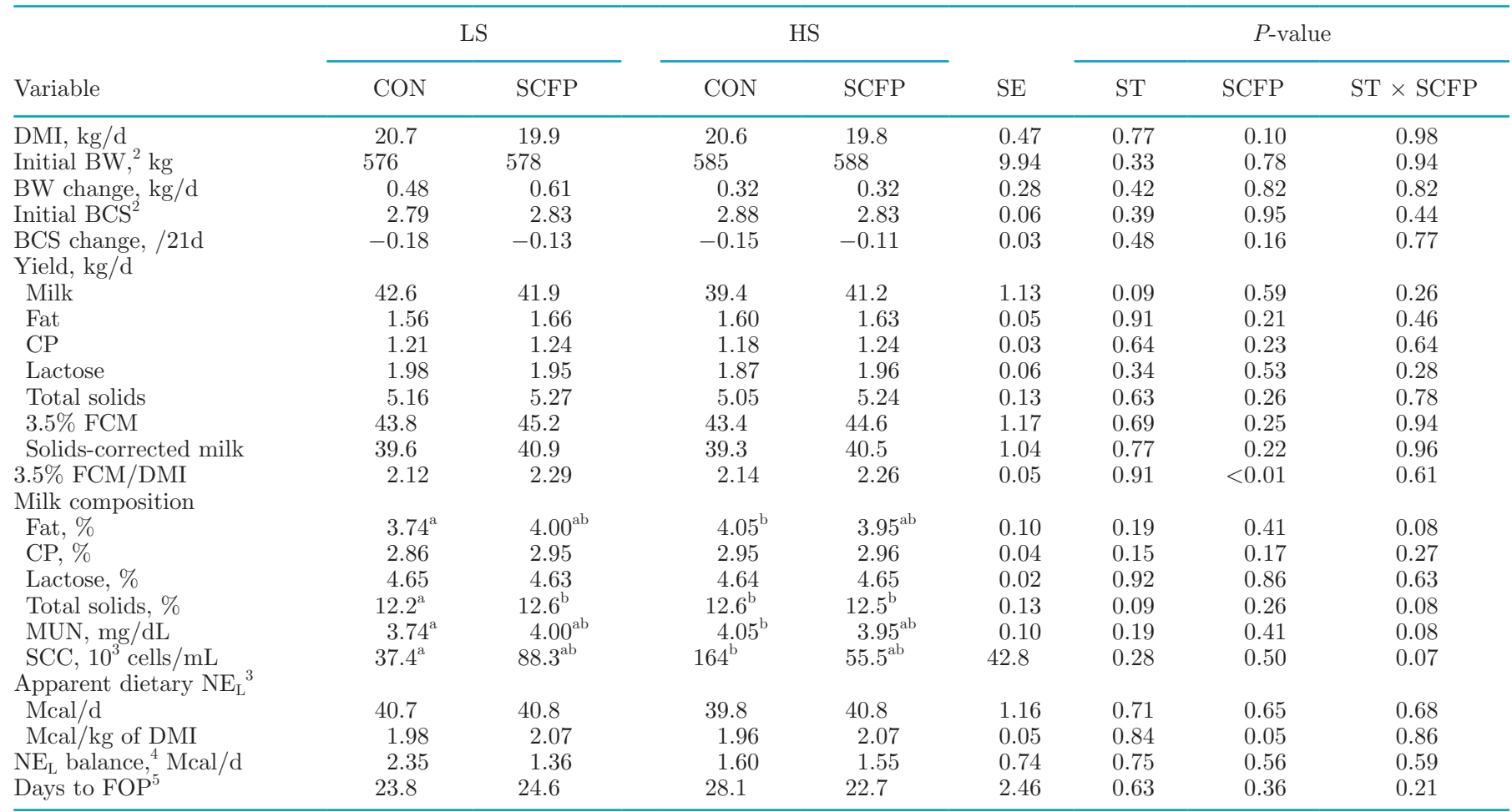

${ }^{\mathrm{a}, \mathrm{b}}$ Means in the same row with different superscripts differ significantly $(P<0.05)$ when an interaction of main treatment effect was observed. ${ }^{1} \mathrm{LS}=$ low-starch fresh diets; HS = high-starch fresh diets; CON = control diet, no SCFP supplementation; SCFP = SCFP-supplemented diet. ${ }^{2}$ Measured on d 23 and $24 \pm 3$ before morning feeding.

${ }^{3}$ Calculated according to Dann et al. (2000).

${ }^{4}$ Apparent dietary $\mathrm{NE}_{\mathrm{L}}(\mathrm{Mcal} / \mathrm{d})$ minus $\mathrm{NE}_{\mathrm{L}}$ required for milk output and maintenance $(\mathrm{Mcal} / \mathrm{d})$. The $\mathrm{NE}_{\mathrm{L}}$ required for milk and maintenance were calculated according to Dann et al. (2000).

${ }^{5}$ Interval from calving to first ovulation postpartum (d).

$(\leq 2.50$ vs. $>2.50)$ are shown in Figure 3. The likelihood of first ovulation occurring by 42 DIM did not differ by starch content of fresh diets (Figure 3a) or by the inclusion of SCFP (Figure 3b). Multiparous cows had a greater likelihood of first ovulation by 42 DIM than primiparous cows (Figure 3c). Cows with higher body condition (BCS >2.50) at 42 DIM had increased likelihood of ovulation by 28 DIM compared with cows with lower body condition (BCS $\leq 2.50$ ); however, no difference was observed in the likelihood of first ovulation by 42 DIM (Figure 3d). Similar to the interval from calving to first ovulation, the occurrence of double ovulation was not affected by dietary treatment (Table 11). However, there was a significant effect of parity, with multiparous cows having greater odds of double ovulation than primiparous cows. In addition, the odds of double ovulation were increased when first ovulation occurred $\leq 28$ compared with $>28$ DIM.

Table 10. Effects of supplementation of a Saccharomyces cerevisiae fermentation product (SCFP) and carryover effects of starch content of fresh diets (ST) on plasma metabolite concentrations on d 42 after calving

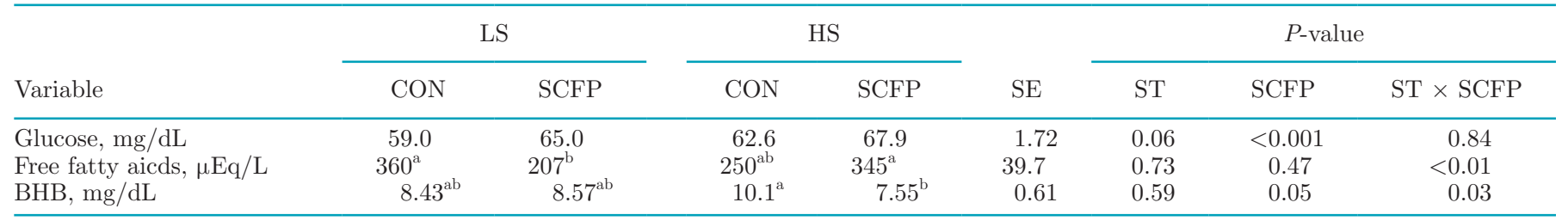

\footnotetext{
${ }^{a, b}$ Means in the same row with different superscripts differ significantly $(P<0.05)$ when an interaction of main treatment effect was observed.
} ${ }^{1} \mathrm{LS}=$ low-starch fresh diets; HS = high-starch fresh diets; CON = control diet, no SCFP supplementation; SCFP $=$ SCFP-supplemented diet. 

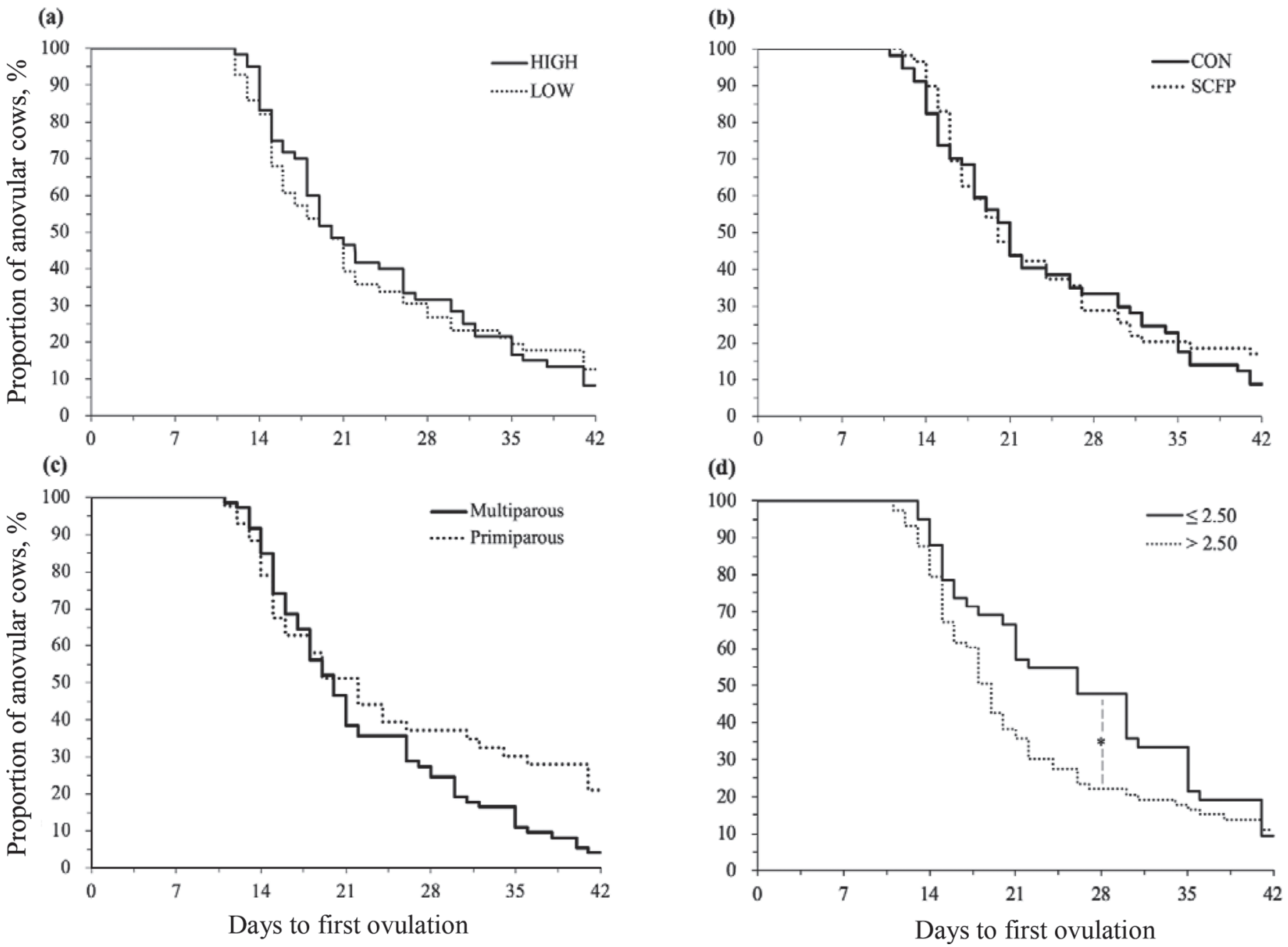

Figure 3. Survival curves of days to first ovulation by 42 DIM according to categories of postpartum dietary starch concentration [high starch (HS) vs. low starch (LS); panel a], supplementation of a Saccharomyces cerevisiae fermentation product [SCFP; control (CON) vs. SCFP; panel b], parity (primiparous vs. multiparous; panel c), and BCS at 42 DIM ( $\leq 2.50$ vs. $>2.50$; panel d). The likelihood of first ovulation occurring by 42 DIM was not different between dietary starch concentration groups [hazard ratio (HR): $0.95,95 \%$ CI: $0.67-1.44, P=0.93$ ] or between SCFP supplementation groups (HR: 0.97, 95\% CI: 0.66-1.42, $P=0.87$ ). Multiparous cows had increased likelihood of first ovulation occurring by 42 DIM compared with primiparous cows (HR: 1.54, 95\% CI: 1.01-2.37, $P=0.04$ ). Cows that had BCS $>2.50$ at 42 DIM had increased likelihood of having first ovulation by 28 DIM (HR: $1.85,95 \%$ CI: $1.14-3.03, P=0.01$ ) compared with cows with BCS $\leq 2.50(*)$; however, the likelihood of first ovulation by 42 DIM was not different.

\section{DISCUSSION}

\section{Effects of Starch Content of Fresh Diets}

In the current study, we found that cows fed LS fresh diets had higher milk yield compared with those fed HS diets during the fresh period. Because the calculated apparent energy density $\left(\mathrm{NE}_{\mathrm{L}}\right)$ of LS and HS diets was similar in the current study and DMI was not affected by dietary starch content, it is unlikely that the increased milk production in LS cows resulted from higher energy intake. Cows fed LS diets tended to lose more BCS and had higher concentrations of plasma free fatty acids and BHB during the fresh period than those fed HS diets, indicating that the increased milk production of LS cows may be partly supported by mobilization of fatty acids from adipose tissue. However, the increased body fat mobilization of LS cows did not negatively affect the health of dairy cows, as suggested by the similar incidence of health disorders for LS and HS cows after calving. In addition, we found an increase in total-tract NDF digestibility for the cows fed LS diets. Increased total-tract NDF digestibility has been reported in other studies when beet pulp was substituted for grain in lactating dairy cows (Voelker and Allen, 2003; Alamouti et al., 2009, 2014) and steers (Mojtahedi and Mesga- 
Table 11. Associations of double ovulation in dairy cows with starch content of fresh diets (ST), supplementation of a Saccharomyces cerevisiae fermentation product (SCFP), parity, and interval to first ovulation ${ }^{1}$

\begin{tabular}{|c|c|c|c|}
\hline Variable & $\begin{array}{c}\text { Incidence of double } \\
\text { ovulation, \% (no./total) }\end{array}$ & $\begin{array}{l}\text { Odds ratio } \\
(95 \% \mathrm{CI})\end{array}$ & $P$-value ${ }^{2}$ \\
\hline \multicolumn{4}{|l|}{ Starch level } \\
\hline LS & $36.5(19 / 52)$ & $0.68(0.30-1.94)$ & 0.57 \\
\hline HS & $41.4(24 / 58)$ & & \\
\hline \multicolumn{4}{|c|}{ SCFP supplementation } \\
\hline $\mathrm{CON}$ & $41.1(23 / 56)$ & $1.02(0.40-2.65)$ & 0.96 \\
\hline SCFP & $37.0(20 / 54)$ & & \\
\hline \multicolumn{4}{|l|}{ Parity } \\
\hline Primiparous & $22.0(9 / 41)$ & $0.30(0.12-0.78)$ & 0.01 \\
\hline Multiparous & $49.3(34 / 69)$ & & \\
\hline \multicolumn{4}{|c|}{ Interval to first ovulation $^{3}$} \\
\hline$\leq 28 \mathrm{~d}$ & $45.7(37 / 81)$ & $3.19(1.08-9.52)$ & 0.04 \\
\hline$>28 \mathrm{~d}$ & $20.7(6 / 29)$ & & \\
\hline
\end{tabular}

ran, 2011). As fiber generally ferments more slowly and consistently in the rumen than starch, energy provided by fiber might have been more favorably partitioned to the mammary gland, which is not responsive to insulin for uptake of glucose, whereas the energy from rapid starch fermentation would be taken up to a greater extent by skeletal muscles and adipose tissue, which respond to insulin (Oba and Allen, 2000). However, we used beet pulp to replace a portion of barley grain to reduce dietary starch content and, as a result, NFC contents were similar between LS and HS diets. The lack of difference in NFC contents of fresh diets in our study may have contributed to the similar $3.5 \%$ FCM among treatments.

Contrary to the results of current study, Rabelo et al. (2003) and McCarthy et al. (2015) reported that animal responses to high-starch diets in DMI or milk yield were greater. The discrepancy between their studies (Rabelo et al., 2003; McCarthy et al., 2015) and our study might be explained by differences in close-up diets that the animals were fed before calving, as proposed by Dann (2016); cows were fed controlled-energy closeup diets in our study to reduce postpartum metabolic complications (Dann et al., 2006; Janovick et al., 2011), but high-starch close-up diets were fed in the previous studies (Rabelo et al., 2003; McCarthy et al., 2015). In the study of Rabelo et al. (2003), even the low-energy close-up diet contained $38.2 \%$ NFC, which was much higher than that of our study $(25.6 \% \mathrm{NFC})$. In the study of McCarthy et al. (2015), starch content of the basal close-up diet was $17.4 \%$, which was 3.6 percentage points higher than the close-up diets used in our study. Considering the effect of NFC fermentation on stimulating the growth of rumen papillae and promot- ing the adaptation of rumen microbial population to diets high in fermentable carbohydrate, the higher starch content of the close-up diets used in those 2 studies may contribute to the greater animal performance with high-starch fresh diets.

In addition, the greater performance of animals fed high-starch fresh diets in Rabelo et al. (2003) and McCarthy et al. (2015) might be related to possible insulin resistance. Previous studies suggested that cows overfed energy during the dry period had higher prepartum insulin concentrations (Dann et al., 2006; Douglas et al., 2006; Janovick et al., 2011) and exhibited a greater degree of insulin resistance at $3 \mathrm{wk}$ postpartum compared with those fed controlled or restricted diets (Holtenius et al., 2003). Insulin resistance, which was suspected in the studies of Rabelo et al. (2003) and McCarthy et al. (2015), might help cows partition energy consistently to milk production regardless of the fermentability of fresh diets. In contrast, cows in our study were fed a controlled-energy close-up diet and likely exhibited less insulin resistance during the fresh period than cows fed the high-energy close-up diets in the studies mentioned above (Rabelo et al., 2003; McCarthy et al., 2015). This may have favored greater glucose uptake by skeletal muscle and adipose tissue and reduced milk yield, particularly when high-starch fresh diets were fed, as more energy was provided in a pulsatile manner from starch fermentation. However, low-starch fresh diets provided more energy from fiber, which ferments more slowly in the rumen and provides energy to animals more consistently, which may have helped partition relatively more energy to the mammary gland. Interestingly, our observations were consistent with that of Dieho et al. (2016), who fed low-energy close-up diets $(9 \%$ starch on a DM 
basis) and reported greater milk yield for cows fed less concentrates during the fresh period. However, we did not measure insulin concentration or insulin resistance in our study, and our speculations need to be evaluated in future studies.

Few studies have investigated the effects of dietary starch on ovarian function. Although some studies (Gong et al., 2002; Dyck et al., 2011) reported a reduction in the interval from calving to first ovulation in cows fed higher levels of dietary starch, others found no difference (Subramaniam et al., 2016; McDougall et al., 2018). In the study by Dyck et al. (2011), cows given a diet with $27 \%$ starch tended have a shorter interval (31 vs. 38 d) from calving to first ovulation than those given a diet containing $23 \%$ starch. In contrast, a larger study (McDougall et al., 2018) reported no difference in the interval from calving to first estrus (36 vs. $33 \mathrm{~d}$ ) between grazing cows that received low- versus high-starch diets (23 vs. $35 \%$ ). Notably, the overall interval from calving to first ovulation was relatively short $(24 \pm 12 \mathrm{~d}$; mean $\pm \mathrm{SD})$ in the present study compared with others. Likewise, the variation in days to first ovulation in this study was minimal, with a high proportion of cows (90\%) having ovulated by 42 DIM compared with a previous study that reported only $68 \%$ of cows resuming ovarian cyclicity by 42 DIM (Bruinjé et al., 2017). The lack of measurable difference and reduced proportion of cows with delayed first ovulation observed here may have affected our power to detect treatment effects.

Dietary starch treatments also had no effect on the incidence of double ovulation. In contrast, Dyck et al. (2011) found that cows fed a high-starch diet had a greater proportion of double ovulation (46 vs. 0\%) than those fed a low-starch diet. Interestingly, the incidence of double ovulation in the present study was increased in cows that had first ovulation $\leq 28$ DIM than $>28$ DIM, although such a trend was not previously observed (Kusaka et al., 2017). The interval to first ovulation and the occurrence of double ovulation were influenced by parity. These results are in accordance with previous studies that reported primiparous cows having an increased interval to first ovulation (Bruinjé et al., 2017) and reduced proportion of double ovulations (Kusaka et al., 2017) compared with multiparous cows.

\section{Effects of SCFP Supplementation}

We hypothesized that SCFP supplementation would enhance dairy cow performance and to a greater extent in dairy cows fed the HS diet than in those fed the LS diet. However, overall DMI and milk yield during the entire fresh period were not affected by SCFP supplementation, and no interactions were detected between
SCFP and dietary starch content. However, we detected a tendency for an interaction between SCFP and day during the first $7 \mathrm{~d}$ after calving: SCFP treatment transiently increased DMI on d 1 and 5 after calving compared with CON. We speculate that SCFP supplementation helped decrease inflammation and stress around calving, increasing DMI immediately after calving. In a companion study (Knoblock et al., 2018), we found that serum haptoglobin concentrations were decreased in SCFP cows on d 7 after calving compared with CON cows, suggesting reduced inflammation in SCFP cows. In addition, Zaworski et al. (2014) reported that SCFPfed cows had decreased serum cortisol concentration, an indicator of stress and pain associated with various health problems (Gross et al., 2015), on d 1 and 3 after calving compared with CON cows, indicating that SCFP supplementation may reduce stress around calving. In addition, Dann et al. (2000) reported higher DMI in cows fed SCFP compared with CON during the last $7 \mathrm{~d}$ of gestation and a tendency for greater DMI for SCFP cows compared with CON cows during d 1 to 21 after parturition.

During the post-fresh period, we found that supplementation of SCFP tended to decrease DMI compared with CON diets. However, concentration of plasma glucose was higher and plasma BHB and free fatty acids concentrations were lower for SCFP-supplemented cows, suggesting that the tendency of lower DMI for cows fed SCFP did not negatively affect the energy status of dairy cows during this period. In addition, yields of milk and $3.5 \% \mathrm{FCM}$ were not reduced by SCFP supplementation during the post-fresh period. In fact, $3.5 \%$ FCM yield was numerically greater for SCFP cows even with the tendency of lower DMI, which contributed to greater feed efficiency for cows fed SCFP. Dann et al. (2000) also reported that feeding SCFP from d 21 before expected calving date to d 42 after calving increased dietary energy supply during the postpartum period. Similar improvements in feed efficiency were reported when SCFP was supplemented to lactating dairy cows (Schingoethe et al., 2004; Cooke et al., 2007). A meta-analysis of the effects of supplementation of SCFP (Diamond V, Cedar Rapids, IA) showed that supplementing SCFP increased DMI by $0.62 \mathrm{~kg} / \mathrm{d}$ for early lactation dairy cows ( $<70$ DIM), but decreased DMI by $0.78 \mathrm{~kg} / \mathrm{d}$ for those in later lactation (>70 DIM), contributing to increased feed efficiency in combination with greater milk production (Poppy et al., 2012). Previous studies have reported the stimulatory effects of SCFP on the growth of cellulolytic and lactate-utilizing bacteria in the rumen (Harrison et al., 1988; Yoon and Stern, 1996; Callaway and Martin, 1997), which could increase the nutrient and energy availability to the animal. Furthermore, feeding SCFP 
has been shown to increase microbial protein synthesis (Erasmus et al., 1992; Hristov et al., 2010) in dairy cows and reduce methane production in sheep (Mwenya et al., 2004). In the current study, we found that supplementation of SCFP decreased MUN concentration compared with CON within the HS group in both the fresh and post-fresh periods. In addition, cows fed SCFP had higher glucose concentration and lower BHB concentration on d $42 \pm 3$ after calving compared with CON cows, suggesting a greater energy supply from the diet. Therefore, the increase in feed efficiency in our study may come from increased energy utilization in the rumen, which is consistent with $5.1 \%$ greater apparent diet $\mathrm{NE}_{\mathrm{L}}$ density for SCFP treatments. Dann et al. (2000) reported that cows fed SCFP had higher apparent $\mathrm{NE}_{\mathrm{L}}$ from feed from d 1 to 42, which was associated with less BW loss in their study. In contrast, SCFP supplementation did not affect postpartum BW change but increased feed efficiency in our study. In addition to the greater energy utilization in the rumen of SCFP cows, reduced inflammation for SCFP cows, as reported by Knoblock et al. (2018), may also contribute to the higher feed efficiency for cows fed SCFP compared with $\mathrm{CON}$ by decreasing the energy requirement for maintenance.

In general, the positive effects of SCFP supplementation were greater during the post-fresh period than the fresh period in the current study, which might be partly attributed to differences in actual SCFP intake. We intended to provide SCFP at $19 \mathrm{~g} / \mathrm{d}$, according to the manufacturer's recommendation, with an assumed DMI of $20 \mathrm{~kg} / \mathrm{d}$. However, DMI during the fresh period was lower, averaging $16.6 \mathrm{~kg} / \mathrm{d}$, which provided 15.7 $\mathrm{g} / \mathrm{d}$ of SCFP (17\% less than the target amount). This may have contributed to the lesser animal responses to SCFP supplementation during the fresh period, and further research is warranted to determine the optimum supplementation level of SCFP during the transition period, when DMI is lower.

\section{CONCLUSIONS}

For dairy cows fed controlled-energy close-up diets, feeding low-starch diets (22\% starch) during the fresh period increased milk production compared with feeding high-starch diets (28\% starch), without affecting DMI but with a tendency for greater BCS loss during the fresh period. During the periparturient period, the effects of supplementation with the $S$. cerevisiae fermentation product on feed intake and milk production were not affected by starch content of fresh diets. In addition, supplementation of the $S$. cerevisiae fermentation product during the periparturient period did not affect overall DMI during the close-up and fresh periods but transiently increased DMI on $\mathrm{d} 1$ and 5 after calving and increased feed efficiency during the post-fresh period. Neither starch content of fresh diets nor supplementation of $S$. cerevisiae fermentation product affected the interval from calving to first ovulation postpartum.

\section{ACKNOWLEDGMENTS}

The authors gratefully acknowledge financial support by Alberta Milk (Edmonton, AB, Canada) and Diamond V Inc. (Cedar Rapids, IA).

\section{REFERENCES}

Alamouti, A. A., M. Alikhani, G. R. Ghorbani, A. Teimouri-Yansari, and M. Bagheri. 2014. Response of early lactation Holstein cows to partial replacement of neutral detergent soluble fibre for starch in diets varying in forage particle size. Livest. Sci. 160:60-68.

Alamouti, A. A., A. Asadi Alamouti, M. Alikhani, G. R. Ghorbani, and Q. Zebeli. 2009. Effects of inclusion of neutral detergent soluble fibre sources in diets varying in forage particle size on feed intake, digestive processes, and performance of mid-lactation Holstein cows. Anim. Feed Sci. Technol. 154:9-23.

Allen, M. S., B. J. Bradford, and M. Oba. 2009. The hepatic oxidation theory of the control of feed intake and its application to ruminants. J. Anim. Sci. 87:3317-3334.

AOAC International. 2000. Official Methods of Analysis. 17th ed. AOAC Int., Gaithersburg, MD.

AOAC International. 2002. Official Methods of Analysis. 17th ed. 1st revision. AOAC Int., Gaithersburg, MD.

Bruinjé, T. C., M. G. Colazo, M. Gobikrushanth, and D. J. Ambrose. 2017. Relationships among early postpartum luteal activity, parity, and insemination outcomes based on in-line milk progesterone profiles in Canadian Holstein cows. Theriogenology 100:32-41.

Callaway, E. S., and S. A. Martin. 1997. Effects of a Saccharomyces cerevisiae culture on ruminal bacteria that utilize lactate and digest cellulose. J. Dairy Sci. 80:2035-2044.

Canadian Council on Animal Care (CCAC). 2009. Guidelines on the care and use of farm animals in research, teaching and testing. Canadian Council on Animal Care, Ottawa, ON.

Cochran, R. C., D. C. Adams, J. D. Wallace, and M. L. Galyean. 1986. Predicting digestibility of different diets with internal markers: Evaluation of four potential markers. J. Anim. Sci. 63:1476-1483.

Cooke, K. M., J. K. Bernard, and J. W. West. 2007. Performance of lactating dairy cows fed whole cottonseed coated with gelatinized starch plus urea or yeast culture. J. Dairy Sci. 90:360-364.

Dann, H. M. 2016. Feeding the fresh cow: What is the ideal carbohydrate mix? Adv. Dairy Technol. 28:71-80.

Dann, H. M., J. K. Drackley, G. C. McCoy, M. F. Hutjens, and J. E. Garrett. 2000. Effects of yeast culture (Saccharomyces cerevisiae) on prepartum intake and postpartum intake and milk production of Jersey cows. J. Dairy Sci. 83:123-127.

Dann, H. M., N. B. Litherland, J. P. Underwood, M. Bionaz, A. D'Angelo, J. W. McFadden, and J. K. Drackley. 2006. Diets during far-off and close-up dry periods affect periparturient metabolism and lactation in multiparous cows. J. Dairy Sci. 89:3563-3577.

Dieho, K., A. Bannink, I. A. L. Geurts, J. T. Schonewille, G. Gort, and J. Dijkstra. 2016. Morphological adaptation of rumen papillae during the dry period and early lactation as affected by rate of increase of concentrate allowance. J. Dairy Sci. 99:2339-2352.

Douglas, G. N., T. R. Overton, H. G. Bateman II, H. M. Dann, and J. K. Drackley. 2006. Prepartal plane of nutrition, regardless of dietary energy source, affects periparturient metabolism and dry matter intake in Holstein cows. J. Dairy Sci. 89:2141-2157.

Dyck, B. L., M. G. Colazo, D. J. Ambrose, M. K. Dyck, and L. Doepel. 2011. Starch source and content in postpartum dairy cow diets: Ef- 
fects on plasma metabolites and reproductive processes. J. Dairy Sci. 94:4636-4646.

Erasmus, L. J., P. M. Botha, and A. Kistner. 1992. Effect of yeast culture supplement on production, rumen fermentation, and duodenal nitrogen flow in dairy cows. J. Dairy Sci. 75:3056-3065.

Erasmus, L. J., P. H. Robinson, A. Ahmadi, R. Hinders, and J. E. Garrett. 2005. Influence of prepartum and postpartum supplementation of a yeast culture and monensin, or both, on ruminal fermentation and performance of multiparous dairy cows. Anim. Feed Sci. Technol. 122:219-239.

Gong, J. G., W. J. Lee, P. C. Garnsworthy, and R. Webb. 2002. Effect of dietary induced increases in circulating insulin concentrations during the early postpartum period on reproductive function in dairy cows. Reproduction 123:419-427.

Gross, J. J., O. Wellnitz, and R. M. Bruckmaier. 2015. Cortisol secretion in response to metabolic and inflammatory challenges in dairy cows. J. Anim. Sci. 93:3395-3401.

Hall, M. B. 2009. Analysis of starch, including malt oligosaccharides, in animal feeds: A comparison of methods and a recommended method for AOAC collaborative study. J. AOAC Int. 92:42-49.

Harrison, G. A., R. W. Hemken, K. A. Dawson, R. J. Harmon, and K. B. Barker. 1988. Influence of addition of yeast culture supplement to diets of lactating cows on ruminal fermentation and microbial populations. J. Dairy Sci. 71:2967-2975.

Holtenius, K., S. Agenäs, C. Delavaud, and Y. Chilliard. 2003. Effects of feeding intensity during the dry period. 2. Metabolic and hormonal responses. J. Dairy Sci. 86:883-891.

Hristov, A. N., G. Varga, T. Cassidy, M. Long, K. Heyler, S. K. R. Karnati, B. Corl, C. J. Hovde, and I. Yoon. 2010. Effect of Saccharomyces cerevisiae fermentation product on ruminal fermentation and nutrient utilization in dairy cows. J. Dairy Sci. 93:682-692.

Huhtanen, P., K. Kaustell, and S. Jaakkola. 1994. The use of internal markers to predict total digestibility and duodenal flow of nutrients in cattle given six different diets. Anim. Feed Sci. Technol. $48: 211-227$.

Janovick, N. A., Y. R. Boisclair, and J. K. Drackley. 2011. Prepartum dietary energy intake affects metabolism and health during the periparturient period in primiparous and multiparous Holstein cows. J. Dairy Sci. 94:1385-1400.

Knoblock, C. E., W. Shi, I. Yoon, and M. Oba. 2018. Feeding a Saccharomyces cerevisiae fermentation product during the periparturient period may decrease inflammation of dairy cows. J. Dairy Sci. 101(Suppl. 2):355. (Abstr.)

Krause, K. M., and G. R. Oetzel. 2006. Understanding and preventing subacute ruminal acidosis in dairy herds: A review. Anim. Feed Sci. Technol. 126:215-236.

Kusaka, H., H. Miura, M. Kikuchi, and M. Sakaguchi. 2017. Incidence of double ovulation during the early postpartum period in lactating dairy cows. Theriogenology 91:98-103.

Littell, C. R., G. A. Milliken, W. W. Stroup, and F. D. Wolfinger. 1996. SAS System for Mixed Models. SAS Inst., Inc., Cary, NC.

McCarthy, M. M., T. Yasui, C. M. Ryan, G. D. Mechor, and T. R. Overton. 2015. Performance of early-lactation dairy cows as affected by dietary starch and monensin supplementation. J. Dairy Sci. 98:3335-3350

McDougall, S., S. Leane, S. T. Butler, J. R. Roche, and C. R. Burke. 2018. Effect of altering the type of dietary carbohydrate early postpartum on reproductive performance and milk production in pasture-grazed dairy cows. J. Dairy Sci. 101:3433-3446.

Mojtahedi, M., and M. D. Mesgaran. 2011. Effects of the inclusion of dried molassed sugar beet pulp in a low-forage diet on the digestive process and blood biochemical parameters of Holstein steers. Livest. Sci. 141:95-103.

Mwenya, B., B. Santoso, C. Sar, Y. Gamo, T. Kobayashi, I. Arai, and J. Takahashi. 2004. Effects of including $\beta 1-4$ galacto-oligosaccha- rides, lactic acid bacteria or yeast culture on methanogenesis as well as energy and nitrogen metabolism in sheep. Anim. Feed Sci. Technol. 115:313-326.

NRC. 2001. Nutrient Requirements for Dairy Cattle. 7th rev. ed. Natl. Acad. Press, Washington, DC.

Oba, M., and M. S. Allen. 2000. Effects of brown midrib 3 mutation in corn silage on productivity of dairy cows fed two concentrations of dietary neutral detergent fiber: 1 . Feeding behavior and nutrient utilization. J. Dairy Sci. 83:1333-1341.

Penner, G. B., K. A. Beauchemin, and T. Mutsvangwa. 2007. Severity of ruminal acidosis in primiparous Holstein cows during the periparturient period. J. Dairy Sci. 90:365-375.

Poppy, G. D., A. R. Rabiee, I. J. Lean, W. K. Sanchez, K. L. Dorton, and P. S. Morley. 2012. A meta-analysis of the effects of feeding yeast culture produced by anaerobic fermentation of Saccharomyces cerevisiae on milk production of lactating dairy cows. J. Dairy Sci. 95:6027-6041.

Rabelo, E., R. L. Rezende, S. J. Bertics, and R. R. Grummer. 2003 Effects of transition diets varying in dietary energy density on lactation performance and ruminal parameters of dairy cows. J. Dairy Sci. 86:916-925.

Ramsing, E. M., J. A. Davidson, P. D. French, I. Yoon, M. Keller, and H. Peters-Fleckenstein. 2009. Effects of yeast culture on peripartum intake and milk production of primiparous and multiparous Holstein cows 1. Prof. Anim. Sci. 25:487-495.

Robinson, P. H. 1997. Effect of yeast culture (Saccharomyces cerevisiae) on adaptation of cows to diets postpartum. J. Dairy Sci. 80:1119-1125

Robinson, P. H., and J. E. Garrett. 1999. Effect of yeast culture (Saccharomyces cerevisiae) on adaptation of cows to postpartum diets and on lactational performance. J. Anim. Sci. 77:988-999.

Schingoethe, D. J., K. N. Linke, K. F. Kalscheur, A. R. Hippen, D. R. Rennich, and I. Yoon. 2004. Feed efficiency of mid-lactation dairy cows fed yeast culture during summer. J. Dairy Sci. 87:4178-4181.

Shen, Y. Z., H. R. Wang, T. Ran, I. Yoon, A. M. Saleem, and W. Z. Yang. 2018. Influence of yeast culture and feed antibiotics on ruminal fermentation and site and extent of digestion in beef heifers fed high grain rations. J. Anim. Sci. 96:3916-3927.

Stone, W. C. 2004. Nutritional approaches to minimize subacute ruminal acidosis and laminitis in dairy cattle. J. Dairy Sci. 87:E13-E26.

Subramaniam, E., M. G. Colazo, M. Gobikrushanth, Y. Q. Sun, A. L. Ruiz-Sanchez, P. Ponce-Barajas, and D. J. Ambrose. 2016. Effects of reducing dietary starch content by replacing barley grain with wheat dried distillers grains plus solubles in dairy cow rations on ovarian function. J. Dairy Sci. 99:2762-2774.

Tyrrell, H. F., and J. T. Reid. 1965. Prediction of the energy value of cow's milk. J. Dairy Sci. 48:1215-1223.

Van Soest, P. J., J. B. Robertson, and B. A. Lewis. 1991. Methods for dietary fiber, neutral detergent fiber, and nonstarch polysaccharide in relation to animal nutrition. J. Dairy Sci. 74:3583-3597.

Voelker, J. A., and M. S. Allen. 2003. Pelleted beet pulp substituted for high-moisture corn: 2. Effects on digestion and ruminal digestion kinetics in lactating dairy cows. J. Dairy Sci. 86:3553-3561.

Wildman, E. E., G. M. Jones, P. E. Wagner, R. L. Boman, H. F Troutt, and T. N. Lesch. 1982. A dairy cow body condition scoring system and its relationship to selected production characteristics. J. Dairy Sci. 65:495-501.

Yoon, I. K., and M. D. Stern. 1996. Effects of Saccharomyces cerevisiae and Aspergillus oryzae cultures on ruminal fermentation in dairy cows. J. Dairy Sci. 79:411-417.

Zaworski, E. M., C. M. Shriver-Munsch, N. A. Fadden, W. K. Sanchez, I. Yoon, and G. Bobe. 2014. Effects of feeding various dosages of Saccharomyces cerevisiae fermentation product in transition dairy cows. J. Dairy Sci. 97:3081-3098. 